\title{
Intercomparison of two comparative reactivity method instruments inf the Mediterranean basin during summer 2013
}

\author{
N. Zannoni ${ }^{1}$, S. Dusanter ${ }^{2,3,4}$, V. Gros ${ }^{1}$, R. Sarda Esteve ${ }^{1}$, V. Michoud ${ }^{2,3}$, V. Sinha ${ }^{5}$, N. Locoge ${ }^{2,3}$, and B. Bonsang ${ }^{1}$ \\ ${ }^{1}$ LSCE, Laboratoire des Sciences du Climat et de l'Environnement, CNRS-CEA-UVSQ, Orme des Merisiers, \\ 91191 Gif sur Yvette, France \\ ${ }^{2}$ Mines Douai, Département Sciences de l'Atmosphère et Génie de l'Environnement (SAGE), 59508, Douai, France \\ ${ }^{3}$ Université Lille 1 Sciences et Technologies, 59655 Villeneuve d'Ascq, France \\ ${ }^{4}$ School of Public and Environmental Affairs, Indiana University, Bloomington, IN, USA \\ ${ }^{5}$ Department of Earth and Environmental Sciences, Indian Institute of Science Education and Research Mohali, \\ Sector 81, S.A.S. Nagar, Manauli PO, Punjab, 140306, India \\ Correspondence to: V. Gros (valerie.gros@1sce.ipsl.fr)
}

Received: 22 April 2015 - Published in Atmos. Meas. Tech. Discuss.: 18 May 2015

Revised: 5 August 2015 - Accepted: 3 September 2015 - Published: 21 September 2015

\begin{abstract}
The hydroxyl radical $(\mathrm{OH})$ plays a key role in the atmosphere, as it initiates most of the oxidation processes of volatile organic compounds (VOCs), and can ultimately lead to the formation of ozone and secondary organic aerosols (SOAs). There are still uncertainties associated with the $\mathrm{OH}$ budget assessed using current models of atmospheric chemistry and direct measurements of $\mathrm{OH}$ sources and sinks have proved to be valuable tools to improve our understanding of the $\mathrm{OH}$ chemistry.

The total first order loss rate of $\mathrm{OH}$, or total $\mathrm{OH}$ reactivity, can be directly measured using three different methods, such as the following: total $\mathrm{OH}$ loss rate measurement, laserinduced pump and probe technique and comparative reactivity method. Observations of total $\mathrm{OH}$ reactivity are usually coupled to individual measurements of reactive compounds in the gas phase, which are used to calculate the $\mathrm{OH}$ reactivity. Studies using the three methods have highlighted that a significant fraction of $\mathrm{OH}$ reactivity is often not explained by individually measured reactive compounds and could be associated to unmeasured or unknown chemical species. Therefore accurate and reproducible measurements of $\mathrm{OH}$ reactivity are required.

The comparative reactivity method (CRM) has demonstrated to be an advantageous technique with an extensive range of applications, and for this reason it has been adopted by several research groups since its development. However,
\end{abstract}

this method also requires careful corrections to derive ambient $\mathrm{OH}$ reactivity.

Herein we present an intercomparison exercise of two CRM instruments, CRM-LSCE (Laboratoire des Sciences du Climat et de l'Environnement) and CRM-MD (Mines Douai), conducted during July 2013 at the Mediterranean site of Ersa, Cape Corsica, France. The intercomparison exercise included tests to assess the corrections needed by the two instruments to process the raw data sets as well as $\mathrm{OH}$ reactivity observations. The observation was divided in three parts: 2 days of plant emissions (8-9 July), 2 days of ambient measurements (10-11 July) and 2 days (12-13 July) of plant emissions. We discuss in detail the experimental approach adopted and how the data sets were processed for both instruments. Corrections required for the two instruments lead to higher values of reactivity in ambient air; overall $20 \%$ increase for CRM-MD and $49 \%$ for CRM-LSCE compared to the raw data. We show that ambient $\mathrm{OH}$ reactivity measured by the two instruments agrees very well (correlation described by a linear least squares fit with a slope of 1 and $R^{2}$ of 0.75 ).

This study highlights that ambient measurements of $\mathrm{OH}$ reactivity with differently configured CRM instruments yield consistent results in a low $\mathrm{NO}_{x}\left(\mathrm{NO}+\mathrm{NO}_{2}\right)$, terpene rich environment, despite differential corrections relevant to each instrument. Conducting more intercomparison exercises, involving more CRM instruments operated under different am- 
bient and instrumental settings will help in assessing the variability induced due to instrument-specific corrections further.

\section{Introduction}

The hydroxyl radical $(\mathrm{OH})$ is the main oxidizing agent in the atmosphere during daytime. It initiates the oxidation of most trace gases emitted by natural and anthropogenic sources and participates in almost all the complex atmospheric chemical pathways. Oxidation of trace gases leads to the production of ozone $\left(\mathrm{O}_{3}\right)$ and secondary organic aerosols (SOAs) which can impact air pollution and climate. With such a role, it is essential to accurately understand both sources and sinks of $\mathrm{OH}$. The main sources of $\mathrm{OH}$ are the following: photolysis of $\mathrm{O}_{3}$, formaldehyde ( $\mathrm{HCHO}$ ) and nitrous acid (HONO), reaction of alkenes with ozone, and recycling from peroxyradicals in low $\mathrm{NO}_{x}\left(\mathrm{NO}+\mathrm{NO}_{2}\right)$ environments (Paulson et al., 1999; Hofzumahaus et al., 2009; Fuchs et al., 2013). Main sinks of $\mathrm{OH}$ are $\mathrm{CO}, \mathrm{CH}_{4}, \mathrm{NO}_{2}$, VOCs (volatile organic compounds) and radicals, mainly $\mathrm{HO}_{2}$. Recent studies report that $\mathrm{OH}$ also reacts quickly with organic peroxy radicals such as $\mathrm{CH}_{3} \mathrm{O}_{2}$, and $\mathrm{OH}+\mathrm{RO}_{2}$ reactions may be a significant sink of $\mathrm{OH}$ in pristine environments (Archibald et al., 2009; Fittschen et al., 2014).

Goldstein and Galbally (2007) have estimated the presence of $10^{4}-10^{5}$ different organics measured in the atmosphere, this number may be only a small part of the species actually present and makes exhaustive measurements of VOCs very challenging and unfeasible with current analytical techniques. In this context, several research groups in the past decade developed methods capable of measuring directly the total sink of $\mathrm{OH}$, termed total $\mathrm{OH}$ reactivity.

Measurements of total $\mathrm{OH}$ reactivity present several advantages. The first one is to obtain direct information on the total $\mathrm{OH}$ sink term in a given environment without the need of measuring every species present in the gas phase. Secondly, since $\mathrm{OH}$ is in a steady state in the atmosphere the balance between $\mathrm{OH}$ production and loss rates can provide additional information on $\mathrm{OH}$ sources (Martinez, 2003; Hens et al., 2014). Moreover, $\mathrm{OH}$ reactivity measurements help to estimate instantaneous ozone production rates and regimes (Sinha et al., 2012). Finally, when mixing ratios of individual gaseous compounds are available at the same site under study, measured total $\mathrm{OH}$ reactivity can be used as a tool for chemical closure of the reactive carbon budget for that specific environment. In this case, we can determine the calculated $\mathrm{OH}$ reactivity as follows:

$k_{\mathrm{OH}}=\sum_{i} k_{i+\mathrm{OH}} \cdot X_{i}$,

with $i$ any measured chemical in the gas phase, $k_{i+\mathrm{OH}}$ the rate coefficient of the reaction between $i$ and $\mathrm{OH}$, and $\mathrm{X}_{i}$ the measured concentration of $i$.
Several studies on simultaneous observations of total $\mathrm{OH}$ reactivity and gaseous compounds have highlighted discrepancies between the total measured $\mathrm{OH}$ reactivity and calculated reactivity, up to $90 \%$ in biogenic dominated environments e.g. Di Carlo et al. (2004); Nölscher et al. (2012b) and Hansen et al. (2014).

The difference between the total measured and the calculated $\mathrm{OH}$ reactivity has been named missing $\mathrm{OH}$ reactivity and has been attributed to unmeasured primary and/or secondary compounds in the atmosphere (Di Carlo et al., 2004; Kim et al., 2011).

Currently, three methods exist to perform direct measurements of total $\mathrm{OH}$ reactivity, such as the total $\mathrm{OH}$ loss rate measurement (TOLRM) (Kovacs and Brune, 2001; Mao et al., 2009; Ingham et al., 2009; Hansen et al., 2014); Pump and probe technique (Calpini et al., 1999; Sadanaga et al., 2004; Yoshino et al., 2006; Lou et al., 2010) and the comparative reactivity method (CRM) (Sinha et al., 2008; Nölscher et al., 2012a; Dolgorouky et al., 2012; Kim et al., 2011; Kumar and Sinha, 2014). A detailed comparison of the three methods can be found in Nölscher et al. (2012a) and Hansen et al. (2015).

Total $\mathrm{OH}$ loss rate measurement consists of a flow tube used to sample ambient air at flow rates in the order of $50-400 \mathrm{sL} \mathrm{min}^{-1}$, wherein a large amount of $\mathrm{OH}$ is added through a movable injector. $\mathrm{OH}$ concentration is quantified at different reaction times using a FAGE apparatus (fluorescence assay by gas expansion, see Faloona et al. (2004) and Dusanter et al. (2009) at the exit of the flow tube by moving the injector, from which a decay curve is obtained due to a change in distance between the $\mathrm{OH}$ source and the $\mathrm{OH}$ detector.

The pump and probe technique was first pioneered by Calpini et al. (1999) and Jeanneret et al. (2001) and then adapted by other groups (Sadanaga et al., 2004, Yoshino et al., 2006 and Lou et al., 2010). The instrument consists of three main parts: a flow tube to sample ambient air, a pulsed laser to generate $\mathrm{OH}$ in the sampling reactor, and a FAGE apparatus to quantify $\mathrm{OH}$. The sampling flow is set around $10-20 \mathrm{sL} \mathrm{min}^{-1}$ and assuming laminar flow the sample has $1 \mathrm{~s}$ residence time for reaction with $\mathrm{OH}$. The hydroxyl radical $\mathrm{OH}$ is generated by ozone photolysis within the reactor and is detected after each laser pulse using the FAGE apparatus to acquire time-resolved $\mathrm{OH}$ decay.

The comparative reactivity method was more recently developed (Sinha et al., 2008). It is an indirect method since $\mathrm{OH}$ is not directly monitored, based on the competition for synthetically generated $\mathrm{OH}$ radicals between a reference molecule, pyrrole, and reactive compounds in ambient air. This is realized in a glass flow reactor where ambient air $\left(\approx 0.25 \mathrm{sL} \mathrm{min}^{-1}\right)$, pyrrole, and $\mathrm{OH}$ are continuously mixed in different stages, with the reactor coupled to a pyrrole detector, most of the time being a proton-transfer reaction mass spectrometer (PTR-MS). The reactivity is obtained 
from changes in pyrrole concentration as a result of the competition inside the reactor for $\mathrm{OH}$ radicals.

The comparative reactivity method exhibits several advantages compared to other existing methods. Among those, the smaller sampling flow needed to run it (since no FAGE apparatus is needed), which broadens the application of the technique to branch and plant enclosure studies for instance; the reader can refer to Kim et al. (2011) and Nölscher et al. (2013) for more information. In addition, several research groups have already a PTR-MS for VOCs' measurements; FAGE instruments are more expensive and require highly skilled operators. These advantages have led to the construction of several CRM instruments throughout the world in the past few years.

Another existing version of the CRM consists of the glass reactor coupled to a Gas Chromatography- Photo Ionization Detector (GC-PID) (Nölscher et al., 2012a), this version is cheaper and more portable but has also demonstrated to be slightly less robust over time compared to the PTR-MS setup.

On the other hand, processing of the raw data and corrections for measurements artifacts represent the main disadvantages of this technique. Previous studies (Sinha et al., 2008; Dolgorouky et al., 2012; Hansen et al., 2015; Michoud et al., 2015) stressed that careful corrections are necessary for CRM measurements and a standardized procedure for data processing has yet to be agreed by the community.

In this study, we present results of the first intercomparison experiment involving two Comparative Reactivity Method instruments, CRM-LSCE (Laboratoire des Sciences du Climat et de l'Environnement) and CRM-MD (Mines Douai) assembled in two different laboratories, run by different operators but working under similar settings. Our study was performed to test a clear and simple approach to process the raw data and accurately derive $\mathrm{OH}$ reactivity values. It aims at identifying potential limitations and getting insights into the robustness of the CRM. Our exercise includes a comparison of calibration factors, correction factors and measurements of $\mathrm{OH}$ reactivity conducted in ambient air (10-11 July) and from a plant enclosure (8-9 July and 12-13 July) to cover a broad range of $\mathrm{OH}$ reactivity (from the limit of detection, $\mathrm{LOD}$, of the instruments up to $300 \mathrm{~s}^{-1}$ ).

\section{Experimental}

\subsection{The comparative reactivity method}

The comparative reactivity method (CRM) relies on the competitive kinetics for $\mathrm{OH}$ radicals between a reference molecule not present in ambient air at normal conditions (i.e. pyrrole $\mathrm{C}_{4} \mathrm{H}_{5} \mathrm{~N}$ ) and reactive species in ambient air. The experiment is conducted in a glass flow reactor coupled to a detector, in our case a proton transfer reaction mass spectrometer (PTR-MS) (Lindinger and Jordan, 1998). The glass

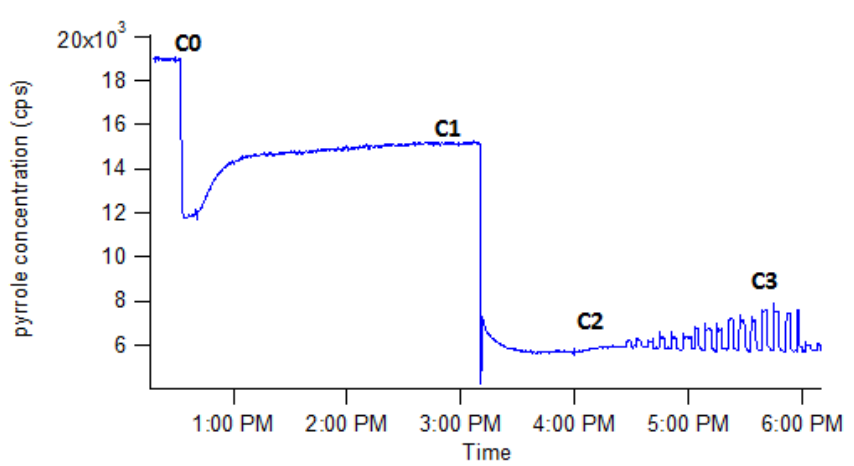

Figure 1. Pyrrole concentration detected by the PTR-MS during a typical $\mathrm{OH}$ reactivity experiment with $\mathrm{CRM}$. C0, C1, C2, C3 are concentrations corresponding to different experimental stages. Technical improvements were done to minimize the difference between $\mathrm{C} 0$ and $\mathrm{C} 1$ reducing pyrrole loss for photolysis.

reactor is equipped with a UV lamp and four arms for flows inlets and outlets; the PTR-MS monitors the concentration of the reference molecule, pyrrole, at any time during the experiment at protonated $m / z 68\left(\mathrm{C}_{4} \mathrm{H}_{5} \mathrm{NH}^{+}\right)$. A detailed description of the reactor and method is available in the publications of Sinha et al. (2008); Nölscher et al. (2012a) and is displayed in Fig. 1.

In brief: (i) a known amount of pyrrole is diluted in the glass reactor with zero air and dry $\mathrm{N}_{2}$, and its concentration is measured with the PTR-MS (C0). Next, (ii) the UV lamp is switched on and photolysis of pyrrole occurs inside the reactor. This is considered our initial concentration of pyrrole and measured as $\mathrm{C} 1$. (iii) The flow of dry $\mathrm{N}_{2}$ is humidified through a bubbler containing high purity water and photolysis of water vapour at $184.9 \mathrm{~nm}$ takes place: at this stage we produce $\mathrm{OH}$ radicals in the system. The fraction of $\mathrm{OH}$ reacted with pyrrole is deduced from the difference between pyrrole initial concentration (C1) and pyrrole concentration when $\mathrm{OH}$ is formed $(\mathrm{C} 2)$. $\mathrm{C} 2$ is the concentration of pyrrole after it has reacted with the $\mathrm{OH}$ produced, following the kinetic rate constant of $1.2 \times 10^{-10} \mathrm{~cm}^{3}$ molecule $\mathrm{s}^{-1} \mathrm{~s}^{-1}$ at $25^{\circ} \mathrm{C}$ (Atkinson et al., 1984; Dillon et al., 2012). Finally, (iv) zero air is replaced by ambient air, and the competitive reaction for the $\mathrm{OH}$ radicals between pyrrole and ambient molecules starts. The level of pyrrole increases depending on the reactivity of $\mathrm{OH}$ reactants in ambient air and pyrrole concentration is recorded as $\mathrm{C} 3$. The higher the concentration and number of reactive species in ambient air, the larger is the reactivity, and broader the difference between $\mathrm{C} 2$ and $\mathrm{C} 3$. Regular switches between $\mathrm{C} 2$ and $\mathrm{C} 3$ permit to determine the total $\mathrm{OH}$ reactivity in ambient air using Eq. (2):

$k_{\mathrm{OH}}=\frac{(\mathrm{C} 3-\mathrm{C} 2)}{(\mathrm{C} 1-\mathrm{C} 3)} \cdot k_{\mathrm{pyrrole}+\mathrm{OH}} \cdot \mathrm{C} 1$,

with $k_{\text {pyrrole }+\mathrm{OH}}$ the rate constant of the reaction between pyrrole and $\mathrm{OH}$. For the derivation of this equation the reader can refer to Sinha et al. (2008). 
In this expression it is assumed that the reaction between pyrrole and $\mathrm{OH}$ follows the pseudo first order kinetics, thus [pyrrole] $>[\mathrm{OH}]$.

Measurements of $\mathrm{OH}$ reactivity with this method are usually conducted with the instrument recording alternatively $\mathrm{C} 2$ and $\mathrm{C} 3$ levels, while $\mathrm{C} 1$ can be monitored less often.

We automatically acquire C2 and C3 by using solenoid valves, which permit fast switches between zero air and ambient air to dilute pyrrole inside the reactor. In the tests reported herein we switch between the two levels every $5 \mathrm{~min}$, to monitor the competition for $\mathrm{OH}$ radicals only and exclude interferences from possible fast humidity changes in ambient air, which can lead to $\mathrm{OH}$ field variations inside the reactor.

Measuring C1 usually takes a longer time, because of lamp warming up when switching from $\mathrm{C} 0$, and mainly because of the time required to dry the reactor completely. For this reason, we tested a new approach on both CRM systems which represents an alternative method to measure the initial concentration of pyrrole (C1). This approach is based on introducing a concentrated reactive molecule into the reactor, with the aim of minimizing pyrrole consumption due to $\mathrm{OH}$ reaction to a negligible fraction. The $\mathrm{OH}$-scavenger has to exhibit a proton affinity lower than water to avoid a consumption of $\mathrm{H}_{3} \mathrm{O}^{+}$inside the PTR-MS, since a large amount of this species is needed to scavenge $\mathrm{OH}$. Tests performed using methane at $30000 \mathrm{ppmv}$ are discussed in Sect. 3.1. This new approach showed to be an excellent alternative since it allows recording $\mathrm{C} 1$ more precisely in only a few minutes compared to hours with the usual method.

\subsection{Data processing}

To process data of $\mathrm{OH}$ reactivity we correct the values obtained from Eq. (1) as follows (see also Hansen et al., 2015; Michoud et al., 2015):

i. correction on $\mathrm{C} 2$ to account for potential differences in humidity between $\mathrm{C} 2$ and $\mathrm{C} 3$ levels;

ii. correction on $\mathrm{C} 3$ to account for some secondary chemistry $\left(\mathrm{HO}_{2}+\mathrm{NO} \rightarrow \mathrm{OH}\right)$ which can lead to a significant production of $\mathrm{OH}$ inside the reactor;

iii. correction on reactivity from Eq. (1) to consider deviation from pseudo first order kinetics (Sinha et al., 2008);

iv. dilution of ambient air inside the reactor.

(i) Zero air and ambient air at different humidity used to dilute pyrrole and acquire respectively C2 and C3 lead to different water content and $\mathrm{OH}$ levels inside the reactor which can produce differences in the two levels and cause an under or overestimation of the reactivity in ambient air. To reduce humidity differences between C2 and C3 we equipped the $\mathrm{CRM}$ with a catalytic converter to generate zero air to acquire $\mathrm{C} 2$. The catalytic converter of CRM-LSCE is made of Pt- Pd pellets heated up to $350^{\circ} \mathrm{C}$, while the one of CRM-MD has
Pt wool also held at $350^{\circ} \mathrm{C}$. However, humidity changes between $\mathrm{C} 2$ and $\mathrm{C} 3$ are still observed and corrections of the raw data of reactivity are often needed.

To look at humidity changes it is useful to monitor the ratio between $\mathrm{m} / \mathrm{z} 37$ and $\mathrm{m} / \mathrm{z} 19$ (here referred as $\mathrm{m37} / \mathrm{m} 19$ ) which corresponds to the protonated mass of the first water cluster normalized for the number of primary ions inside the PTR-MS (see Ammann et al., 2006 and Sinha et al., 2009) and depends on the absolute humidity of the air sampled. For instance, if zero air has a lower humidity than ambient air, the ratio $m 37 / m 19$ will be smaller for $\mathrm{C} 2$ compared to $\mathrm{C} 3$, which will result in a smaller difference between $\mathrm{C} 2$ and $\mathrm{C} 3$ and an underestimation of the reactivity in ambient air. In addition, humidity differences can also vary in opposite directions (C2 can have lower humidity than $\mathrm{C} 3$ and vice versa).

To quantify this type of correction we inject in the reactor a known amount of dry clean air and produce in this way a $\mathrm{C} 2$ level that differs from the actual $\mathrm{C} 2$ only for a different humidity (referred in this study as $\mathrm{C} 2 *$ ). Levels of $\mathrm{C} 2$ are plotted vs. $m 37 / m 19$ ratio recorded during C2 (see Fig. 2).

We correct therefore the measured C2 by applying Eq. (3):

$$
\begin{aligned}
\mathrm{C} 2_{\text {corrected }} & =\mathrm{C} 2+p \cdot\left[(m / z 37 / m / z 19)_{\text {duringC } 3}\right. \\
& \left.-(m / z 37 / m / z 19)_{\text {duringC2 }}\right]
\end{aligned}
$$

where $p$ corresponds to a mean value of the slopes from the linear least squares fits obtained from different tests on the field and represented in Fig. 2. A comparison on the humidity correction for the two CRMs will be presented in Sect. 3.2. (ii) When the UV lamp is switched on, photolysis of water vapour at $184.9 \mathrm{~nm}$ occurs as follows:

$\mathrm{H}_{2} \mathrm{O} \rightarrow \mathrm{OH}+\mathrm{H}$.

$\mathrm{H}$ recombines with $\mathrm{O}_{2}$ present in zero air to rapidly generate $\mathrm{HO}_{2}$ :

$\mathrm{H}+\mathrm{O}_{2}+\mathrm{M} \rightarrow \mathrm{HO}_{2}+\mathrm{M}$

$\mathrm{HO}_{2}$ can react with $\mathrm{NO}$, if this is present in the sampled air, to generate $\mathrm{OH}$ :

$\mathrm{NO}+\mathrm{HO}_{2} \rightarrow \mathrm{OH}+\mathrm{NO}_{2}$

This secondary source of $\mathrm{OH}$ leads to a lower level of $\mathrm{C} 3$, the magnitude of which depends on the amount of ambient NO. This artifact leads to an underestimation of the $\mathrm{OH}$ reactivity in ambient air and can even result in negative values. A detailed description on how to assess the sensitivity of the CRM to NO and how to quantify the correction for this artifact is described elsewhere (Dolgorouky et al., 2012; Hansen et al., 2015; Michoud et al., 2015). During our intercomparison exercise the level of NO in ambient air reached a maximum of $1 \mathrm{ppbv}$, which resulted in negligible secondary formation of $\mathrm{OH}$ inside our two systems, therefore no corrections were warranted here. (iii) It is assumed in Eq. (1) 


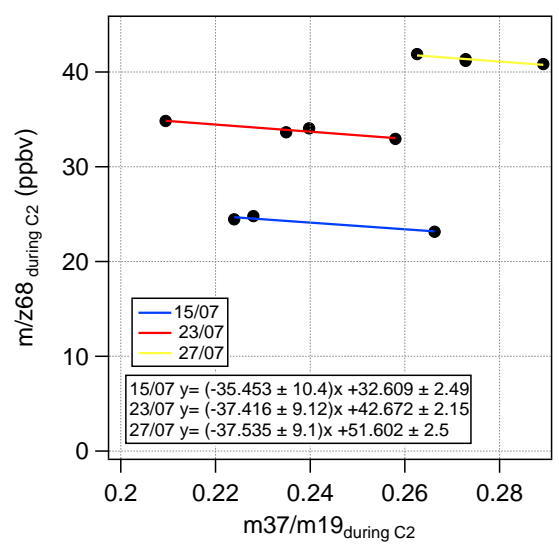

Figure 2. Linear least squares fit of $m / z 68$ during C2 vs. $m 37 / m 19$ during $\mathrm{C} 2$ for the tests conducted on the field to assess the correction for humidity differences between $\mathrm{C} 2$ and C3 for CRM-LSCE. Equation coefficients are reported with one standard deviation. Differences in the intercepts are due to a less efficient tracking of absolute humidity from $m 37 / m 19$ on a longer time scale.

that reactions of $\mathrm{OH}$ with pyrrole and ambient trace gases proceed through first order kinetics, i.e. pyrrole and trace gas concentrations are higher than $\mathrm{OH}$ concentration. However, CRM instruments are operated with $\mathrm{OH}$ concentrations on the same order of magnitude than pyrrole ([pyrrole] $\sim 60$ 70 ppbv, $[\mathrm{OH}] \sim 40-50 \mathrm{ppbv}$ ) and a correction must be applied to account for a deviation from first order kinetics. A correction factor $F$ can be obtained theoretically (Sinha et al., 2008) or experimentally (as in this study and in Hansen et al., 2015; Michoud et al., 2015) and used to process reactivity data already corrected for humidity changes and secondary $\mathrm{OH}$ formation as follows:

$k_{\mathrm{OH}_{\text {corrected }}}=k_{\mathrm{OH}_{\text {measured }}} \cdot F$.

Previous studies used simple numerical simulations to determine such correction factor. Simulations were run at pyrroleto-OH ratio of 10 , near pseudo first order condition, and 1.22, experimental conditions, for more information see Sinha et al. (2008). A fitting function is obtained from simulations in the experimental conditions which showed that if a correction is not taken into account, measurements of $\mathrm{OH}$ reactivity can be overestimated for low values of pyrrole-to-OH ratio.

In our study, we use an experimental approach to correct for deviations from first order kinetics, which can be more representative of the complex chemistry occurring inside the reactor.

To do so, we introduce inside the reactor a known amount of a standard gas whose reactivity with $\mathrm{OH}$ is well determined and reported in literature. We test the instrument response over a broad range of reactivity, for instance from the LOD to $300 \mathrm{~s}^{-1}$, for different standard gases and different pyrrole-to-OH ratios. From each test a linear least squares fit for the measured $\mathrm{OH}$ reactivity vs. the injected reactivity is obtained, and the inverse of the slope is then reported for every pyrrole-to-OH ratio investigated. In such way, we obtain a correction factor which is instrument specific for the experimental conditions adopted.

In our intercomparison exercise we used as test gases propane and ethane, with ethane being the same standard gas for both instruments. Results of these tests are shown in Sect. 3.3. (iv) $\mathrm{OH}$ reactivity values obtained from Eq. (1) and corrected for humidity changes, secondary $\mathrm{OH}$ formation, and deviation from first order kinetics, are then corrected for the dilution of ambient air sampled inside the reactor. The dilution factor is calculated as the ratio between the sampling flow rate and the total flow rate inside the reactor (sum of flow rates of $\mathrm{N}_{2}$, pyrrole and ambient air).

\subsection{Comparative Reactivity Method set up}

A description of the two CRM instruments used in this study, including operating conditions, is given below. It is illustrated by a detailed description of the instrument constructed at LSCE (Laboratoire des Sciences du Climat et de l'Environnement) in Fig. 3 and differences with the one from MD (Mines Douai) are reported in Table 1 and discussed below.

The comparative reactivity method instrument assembled at LSCE is a modified version of the CRM used during the MEGAPOLI field campaign and presented in Dolgorouky et al. (2012). Briefly, pyrrole (Westfalen, Germany, $10.2 \mathrm{ppmv}$ in $\mathrm{N}_{2}, 20 \%$ uncertainty), zero air (Messer standard mixture) and $\mathrm{N}_{2}$ (Messer, purity $99.9999 \%$ ) are injected in a glass flow reactor (same shape and size as the one described by Sinha et al., 2008) and pyrrole concentration is monitored with a PTR-MS (High sensitivity quadrupole, from IONICON Analytic GmbH, Innsbruck, Austria). Zero air is obtained from synthetic air to achieve dry conditions for the acquisition of $\mathrm{C} 1$ and from sampling ambient air through a catalytic converter to generate zero air at ambient $\mathrm{RH}$ when measuring C2. A pump is placed at the exhaust of the cell, therefore the total flow is driven inside the reactor by the pump at the exhaust and the PTR-MS sampling. A UV pen ray Hg lamp (Lot Oriel, France) emitting at $184.9 \mathrm{~nm}$ is used to produce hydroxyl radicals. The total flow rate inside the reactor is usually kept around $0.3 \mathrm{sL} \mathrm{min}{ }^{-1}$, with a concentration of pyrrole in the range of 20-30 ppbv in the $\mathrm{C} 2$ level, $\mathrm{C} 1$ of $65 \pm 5.8 \mathrm{ppbv}(1 \sigma)$ and pyrrole-to-OH ratio ranging from 1.2 to 2.6.

A three-way valve is used to inject an external gas standard inside the sampling line. Additions of a standard test gas permit to derive the correction for a deviation from first order kinetics (see Sect. 3.3). A four-way valve is used to switch automatically every 5 min between $\mathrm{C} 2$ (zero air from the catalytic converter) and C3 (ambient air). An additional pump is used to either flush the sampling line with ambient air while the system is measuring $\mathrm{C} 2$ or to flush the catalytic converter while the system is measuring C3. Sampling lines for the re- 
Table 1. Technical parts and operational settings of CRM LSCE and CRM MD during the intercomparison excercise. MPI stands for Max Planck Institute (chemistry division, Mainz, Germany).

\begin{tabular}{|c|c|c|}
\hline & CRM-LSCE & CRM-MD \\
\hline Reactor & glass reactor from MPI & glass reactor from MPI \\
\hline Detection system & $\begin{array}{l}\text { PTR-QMS (from IONICON, Innsbruck, Aus- } \\
\text { tria) }\end{array}$ & $\begin{array}{l}\text { PTR-ToFMS (second generation, } \\
\text { Kore Technology Ltd, Ely, UK) }\end{array}$ \\
\hline \multicolumn{3}{|l|}{ Sampling for $\mathrm{kOH}$ in ambient air } \\
\hline -flow rate $\left(\mathrm{sL} \mathrm{min}^{-1}\right)$ & 0.25 & 2 \\
\hline -residence time $(\mathrm{s})$ & $\sim 3$ & $\sim 3$ \\
\hline \multicolumn{3}{|l|}{ Sampling for $\mathrm{kOH}$ plant enclosure } \\
\hline -line OD /length (inches/ m) & $1 / 8^{\prime \prime} / 3+1 / 4^{\prime \prime} / 2.5$ & $1 / 4^{\prime \prime} / 30$ \\
\hline -flow rate $\left(\mathrm{sL} \mathrm{min}^{-1}\right)$ & 0.25 & 2 \\
\hline -residence time (s) & $\sim 14$ & $\sim 16$ \\
\hline Sampling set up & $\begin{array}{l}\text { no pump before sampling, PTFE filter at } \\
\text { the inlet }\end{array}$ & $\begin{array}{l}\text { Teflon pump between sampling } \\
\text { line and reactor, } \\
\text { no filter at the inlet }\end{array}$ \\
\hline Total flow inside reactor $\left(\mathrm{sL} \mathrm{min}^{-1}\right)$ & $\sim 0.33$ & $\sim 0.355$ \\
\hline Photolysis rate $(\%)$ & $\sim 5$ & $\sim 2$ \\
\hline $\mathrm{C} 1$ value (ppbv) & $\begin{array}{l}\text { interpolated over the measured } \mathrm{C} 1 \text { dry } \\
65 \pm 5.8(1 \sigma)\end{array}$ & $\begin{array}{l}\text { from methane test } \\
61.4 \pm 0.6(1 \sigma)\end{array}$ \\
\hline Systematic uncertainty (\%) & 35 & 18 \\
\hline $\operatorname{LOD}\left(s^{-1}\right)(3 \sigma)$ & 3 & 3 \\
\hline
\end{tabular}

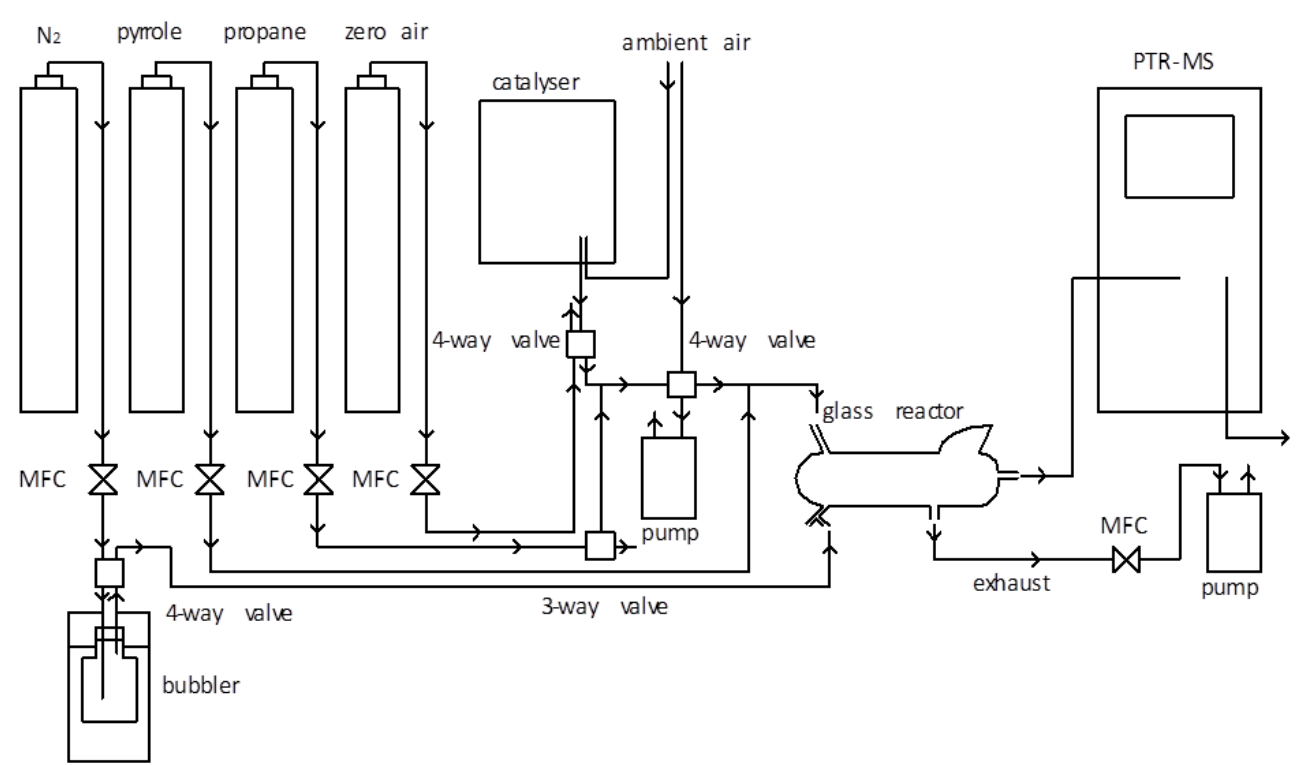

Figure 3. Simplified not-to-scale schematic of the comparative reactivity method instrument of LSCE. Known flows of pyrrole, $\mathrm{N}_{2}$, and zero air are injected into a glass flow reactor. A four-way manual valve is used to humidify the flow of nitrogen, when $\mathrm{OH}$ radicals production is required. A four-way automatic valve allows for fast switches between C2 and C3 stages. A known amount of an external standard (in this case, propane) can be injected in the reactor to calibrate the instrument through a three-way valve.

actor and the catalytic converter are collocated to reduce humidity variations when measuring $\mathrm{C} 2$ and $\mathrm{C} 3$. Although the humidity difference between $\mathrm{C} 2$ and $\mathrm{C} 3$ is reduced with a catalytic converter, we still observe differences between the two levels; therefore, we correct the raw data as reported in the data processing section.

Five mass flow controllers are used to control the flow rates, including pyrrole, synthetic air, $\mathrm{N}_{2}$, external standard (for instance propane), and the flow rate at the exhaust to en- 
sure a constant and precise dilution of pyrrole and ambient air during the measurements. An opening for an overflow is placed before the mixing of zero air with the external standard and is kept around $0.01-0.02 \mathrm{sL} \mathrm{min}^{-1}$, to avoid any pressure build up in the system and to provide an outlet to check flows stability at any time. CRM-LSCE measures total $\mathrm{OH}$ reactivity automatically, except for manual quality check controls (external standard injection), and $\mathrm{C} 1$ acquisition.

The dwell time for the acquisition of $m / z 68$ is $20 \mathrm{~s}$, and C2-C3 switches are performed every $5 \mathrm{~min}$, leading to $\mathrm{OH}$ reactivity measurements every $10 \mathrm{~min}$. The LOD of LSCECRM is $\sim 3 \mathrm{~s}^{-1}(3 \sigma)$ and the systematic uncertainty is $\sim 35 \%(1 \sigma)$, including uncertainties on the rate coefficient between pyrrole and $\mathrm{OH}(8 \%)$, detector sensitivity changes and pyrrole standard concentration (22\%), correction factor for kinetic regime $(26 \%)$ and flows fluctuations $(2 \%)$.

Potential measurement artifacts discussed in Sinha et al. (2008) are either corrected for the CRM-LSCE system or negligible under characteristic ambient conditions of the measuring site. In particular, photolysis is quantified to be $\sim 5 \%$; humidity changes are corrected as reported in the data processing section and $\mathrm{OH}$ formation by $\mathrm{HO}_{2}+\mathrm{NO}$ is negligible.

The CRM-MD instrument is described elsewhere (Hansen et al. 2015; Michoud et al., 2015). For this study, several improvements were performed compared to the instrument described in Hansen et al. (2015), to achieve a lower pyrrole photolysis in the reactor $(<5 \%)$, and by consequence, to reduce the potential photolysis of other trace gases. The CRMMD instrument was operated under the same conditions of flow rates, pyrrole concentration, and pyrrole-to- $\mathrm{OH}$ ratios as the LSCE instrument to allow an assessment of the reproducibility of $\mathrm{OH}$ reactivity measurements using the CRM technique. CRM-MD exhibits similar figures of merit than CRM-LSCE, including a detection limit $(3 \sigma)$ of $3 \mathrm{~s}^{-1}$ and a systematic error quantified to be $\sim 18 \%(1 \sigma)$. Differences in uncertainty between the two instruments can be explained by different uncertainties $(1 \sigma)$ on the concentration of the pyrrole standard used (20\% for CRM-LSCE and $5 \%$ for CRMMD) and uncertainties in the correction factors applied for deviations from first order kinetics (26\% for CRM-LSCE while $9 \%$ for CRM-MD).

The main differences between both instruments are listed in Table 1 and are discussed below:

i. Choice of the detector; both have a proton transfer reaction mass spectrometer: quadrupole from IONICON Analytik, Austria for LSCE and Time of Flight from KORE Technology, UK for MD.

ii. The sampling point during the ambient $\mathrm{kOH}$ experiment: the sampling lines of the two instruments were placed on top of each trailer, about $30 \mathrm{~m}$ far from each other, and $2 \mathrm{~m}$ different in height. The length of the sampling lines was the same, while the outer diameter size and sampling flow rates differ to have a similar residence time of the sample in the lines of about $3 \mathrm{~s}$.

iii. The length of the sampling line during the enclosure $\mathrm{kOH}$ experiment: approximately $30 \mathrm{~m}$ for CRM-MD and $5.5 \mathrm{~m}$ for CRM-LSCE. A longer sampling line was used for CRM-MD to perform collocated measurements with CRM-LSCE. However, the sampling flow rate was adjusted to $2 \mathrm{~L} \mathrm{~min}^{-1}$ to get similar residence times in the sampling lines of the two instruments (approximately 14 and 16 s for CRM-LSCE and CRM-MD, respectively).

iv. The sampling strategy: CRM-MD is equipped with a Teflon pump between the sampling line and the reactor while CRM-LSCE has the sampling line directly connected to the reactor, without any pump. The extra flow from the pump is vented through an open T-connector and similar sampling flow rates are achieved for both instruments. In addition, the sampling line of CRM-LSCE has a PTFE filter at the inlet to exclude particles with a diameter larger than $0.25 \mu \mathrm{m}$ entering the reactor, while CRM-MD has no filters at the inlet.

In addition, each instrument uses a different pyrrole standard, i.e. from Westfalen, Germany (10.2 ppmv in $\mathrm{N}_{2}, 20 \%$ uncertainty, $1 \sigma$ ) for CRM-LSCE and from PRAXAIR Inc., France (10.1 ppmv in $\mathrm{N}_{2}, 5 \%$ uncertainty, $1 \sigma$ ) for CRM-MD. There are legitimate concerns that differences in the $\mathrm{OH}$ reactivity measurements could be due to the pyrrole standard since this type of gas cylinder is not common. In order to estimate the impact of using two different standards on the intercomparison results, the standard from Mines Douai was tested on the LSCE instrument, which instead was calibrated using the LSCE standard. The concentration of pyrrole measured in the MD cylinder was $9170 \pm 272 \mathrm{ppbv}$, which is less than $10 \%$ different of the certified concentration of $10.1 \mathrm{ppmv}$.

\subsection{Description of the field site and experiments}

The two CRM instruments were deployed from the 8-13 July 2013 at a remote site, Ersa, Cape Corsica, France $\left(42.97^{\circ} \mathrm{N}\right.$, $9.38^{\circ} \mathrm{E}$, alt $\left.533 \mathrm{~m}\right)$. The site was chosen for intensive monitoring of atmospheric trace gases and aerosols under the ChArMEX project (Chemistry and Aerosols in a Mediterranean Experiment), an international program of field monitoring and modelling of atmospheric properties and climate interactions over the Mediterranean basin (https://charmex. lsce.ipsl.fr/). $\mathrm{OH}$ reactivity was measured as part of the 2013 CARBOSOR (CARBOn within continental pollution plumes: SOurces and Reactivity) field campaign by CRMLSCE from the 16 July-5 August.

The field site is located in the northern part of cape Corsica on the top of a hill facing the Mediterranean sea (533 m a.s.1.) and a few $\mathrm{km}$ away from the coast $(2.5,4.5$, and $6 \mathrm{~km}$ from the west, north and east side respectively). The site is char- 
acterized by an intense Maquis shrubland, including characteristic plant species of the Mediterranean ecosystem as Pistacia Lentiscus, Myrtus Communis, Cistus Monspeliensis, Rosmarinus Officinalis, Genisteae, Hellebores and others. The closest anthropogenic source is the city of Bastia, second largest city and main harbour of the island, $50 \mathrm{~km}$ southern the monitoring site.

The intercomparison exercise consisted of three periods of collocated measurements of $\mathrm{OH}$ reactivity (between 8 and 9 July, between 10 and 11 July and during 12-13 July) and tests to evaluate the data processing using a common procedure.

During these days, ambient reactivity was close to the LOD of the systems; therefore we decided to measure the reactivity of a plant species close to our trailers and known to emit highly reactive compounds as monoterpenes (BrachoNunez et al., 2011). The plant we chose is a Rosmarinus officinalis, commonly known as rosemary, found in low shrubs with evergreen needle-like leaves and native to the Mediterranean region.

For this experiment, we placed our inlets in a small enclosure constructed from a PET flask and showed to not interfere with ambient measurements. We chose it to prevent the sampling lines from rain and wind exposure and concentrate the emissions from the plant. From time to time we induced higher emissions by applying some mechanical stress (for instance by scraping or cutting some small branches); hence the results reported in the next section are not indicative for the plant's natural emissions. Figure 4 shows a top view of the field site and respective position of the two instruments.

\section{Results and discussion}

In the following section we present results of the intercomparison exercise and tests run on the two instruments to define a common and consistent approach to evaluate the data of $\mathrm{OH}$ reactivity. Tests include measurement of $\mathrm{C} 1$ according to the conventional approach presented in the experimental section and reported by Sinha et al. (2008) as well as measurement of $\mathrm{C} 1$ according to a new approach based on the use of an $\mathrm{OH}$ scavenger. We show results from collocated measurements of $\mathrm{OH}$ reactivity and the corrections needed for both instruments, and how corrections influence the correlation of the results of the two instruments.

\section{1 $\mathrm{C} 1$ acquired with the conventional and scavenger approaches}

The initial concentration of pyrrole, named $\mathrm{C} 1$, is usually measured when pyrrole is mixed with dry zero air and dry nitrogen, with the mercury lamp on. However, switching from humid to dry air to get a complete drying of the reactor can often be time consuming, especially when the instrument is operating on the field.
For this reason we conducted the experiment to inject a known amount of a scavenger molecule, in this case methane, into the CRM reactors to reach a mixing ratio of approximately $3 \%$ by volume.

Figure 5 shows three measurements of $\mathrm{C} 1$ performed with CRM- LSCE at flow rates of 12,8 , and $0.014 \mathrm{sL} \mathrm{min}^{-1}$ of methane mixed in a total flow of about $0.330 \mathrm{sL} \mathrm{min}^{-1}$, leading to $\mathrm{CH}_{4}$ mixing ratios of $3.4,2.3$ and $4.0 \%$ respectively. At 11:30 (CEST), the PTR-MS was measuring C2, the cell was wet, pyrrole mixing ratio was $24.3 \pm 0.4 \mathrm{ppbv}$ and $m / z \quad 37$ signal was $1.25 \times 10^{6} \mathrm{cps}$. At $11: 40$ we injected methane at the three flow rates indicated above and pyrrole mixing ratio increased to $73.5 \pm 0.6,71 \pm 0.5$ and $72.6 \pm 2.9 \mathrm{ppbv}$ inside the cell. It can be noticed, that we measured the same concentration of pyrrole when different flow rates of methane were added into the reactor, suggesting that only a negligible fraction of $\mathrm{OH}$ reacts with pyrrole and most of $\mathrm{OH}$ is scavenged by methane.

$\mathrm{C} 1$ was then also acquired under dry conditions, with $\mathrm{m} / \mathrm{z} 37$ being $2.35 \times 10^{5} \mathrm{cps}$, i.e. 1 order of magnitude lower than under wet conditions, at time 12.30. In this case, the pyrrole mixing ratio reached $73.8 \pm 2.9 \mathrm{ppbv}$, which is not significantly different from the concentration measured using the scavenger approach. In this specific experiment, the acquisition of $\mathrm{C} 1$ with the usual approach took approximately $20 \mathrm{~min}$, this time can vary to hours depending on the reactor design and coating.

For the CRM-LSCE instrument, similar values of $\mathrm{C} 1$ were found using both methodologies, highlighting the feasibility of the scavenger approach. Similar tests performed on the CRM-MD instrument showed significant differences in C1 values measured using the two approaches, with higher $\mathrm{C} 1$ values when the scavenger was used. This disagreement is likely due to difficulties to completely dry the reactor for the CRM-MD instrument, leading to the formation of $\mathrm{OH}$ from the photolysis of residual water molecules, which in turn leads to an underestimation of $\mathrm{C} 1$. The scavenger approach appeared to give a more robust determination of $\mathrm{C} 1$ for this instrument. Similar tests were also conducted in the laboratory after the ChArMEx field campaign using propane as a scavenger (at approximately 900 ppmv), showing consistent results with field observations.

The scavenger approach appears to be more suitable for field deployments than the conventional approach for CRM instruments, where drying requires more than an hour, since it allows faster $\mathrm{C} 1$ measurements (response in a few minutes against hours depending on the reactor's conditions), allowing more frequent checks of pyrrole stability without impairing ambient measurements of $\mathrm{OH}$ reactivity.

\subsection{Assessment of the correction for humidity differences between $\mathrm{C} 2$ and $\mathrm{C} 3$}

As mentioned in Sect. 2.2, the correction on the C2 measurement aims at reducing artifacts due to different humidity 


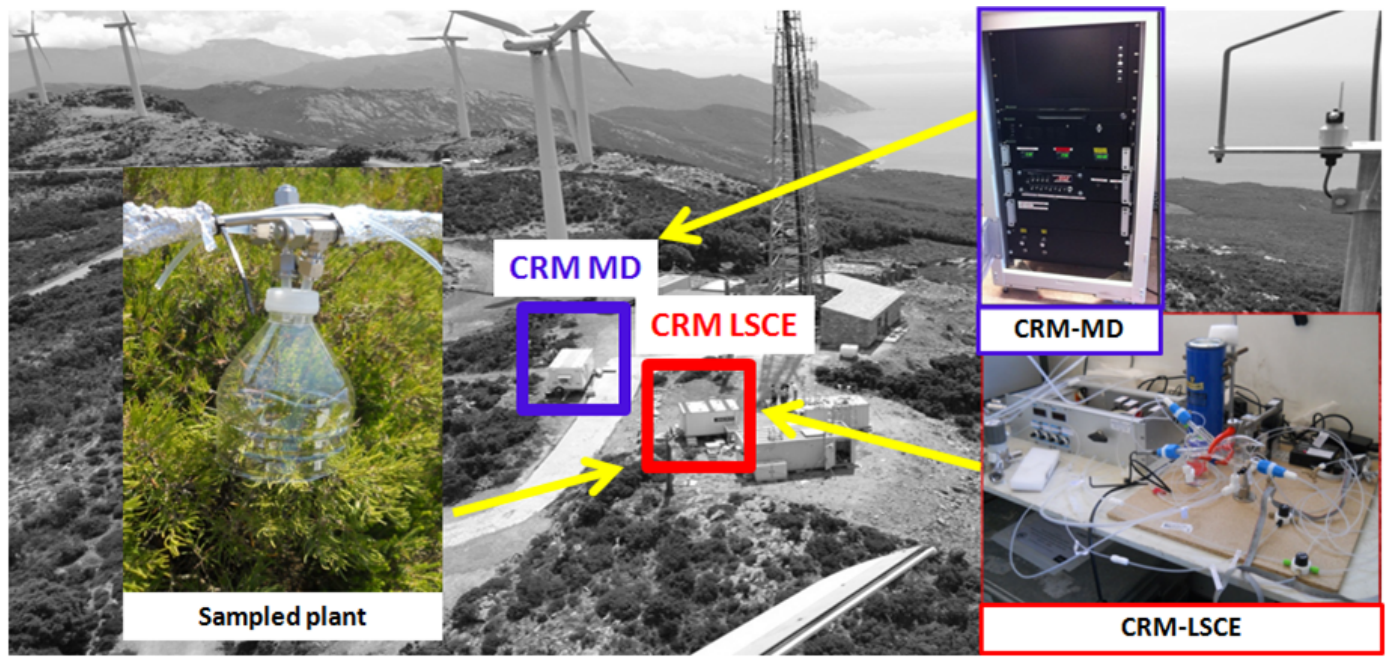

Figure 4. Top view of the field site at Cape Corsica. Relative distances between the trailers containing the instruments, details of the instruments and sampled plant species are provided.

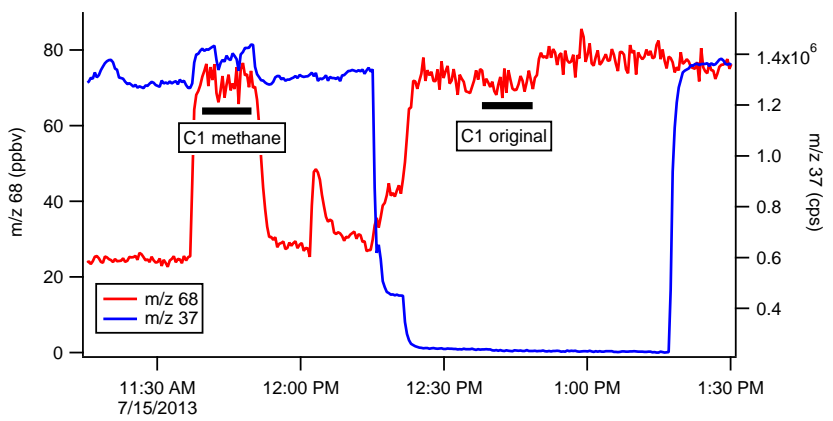

Figure 5. Comparison between $\mathrm{C} 1$ acquired with the $\mathrm{OH}$ scavenger approach and with the original approach. Values of $m / z 37$ refer to the protonated first water cluster which is used as tracer for absolute humidity in the system and depends on PTR-MS operational conditions, in our case $E / N=120 \mathrm{Td}$.

levels between $\mathrm{C} 2$ and $\mathrm{C} 3$ measurements. While differences in humidity are already reduced using a catalytic converter to generate zero air from ambient air, small differences are still observed on the $m 37 / m 19$ ratio, which in turn can lead to significant errors in $\mathrm{OH}$ reactivity measurements if $\mathrm{C} 2$ is not corrected.

Both CRM instruments were characterized in the laboratory and several times during the field experiment to quantify the C2-dependence on humidity.

Calibrations for humidity consist of modulating the humidity of wet zero air flowing inside the reactor while recording $\mathrm{C} 2$ by mixing the wet zero air with dry zero air at different ratios inside the reactor. In this way, we monitor $\mathrm{C} 2$ (ambient humidity) and $\mathrm{C}^{*}$ (ambient humidity mixed with dry synthetic air) signals, and alternate rapidly between them to avoid any interference from local ambient humidity changes. Values of $\mathrm{C} 2$ acquired in this way are plotted vs. the normal- ized counts of the first water cluster $(m 37 / m 19)$ during $\mathrm{C} 2$ as shown in Fig. 2. A linear least squares fit of $m / z 68$ (during C2) vs. $m 37 / m 19$ (during $\mathrm{C} 2$ ) provide the equation used to correct C2 as described in Sect. 2.2.

We performed simultaneous measurements of $\mathrm{OH}$ reactivity during 8-13 July 2013 and processed the raw data as reported in Sect. 2.2. We found that the correction for humidity differences applied to the raw data sets has an average impact of $12 \%$ for CRM-LSCE and $4 \%$ for CRM-MD (see Table 2). Interestingly, these corrections resulted in an increase of the CRM-LSCE measurements and in a decrease of the CRMMD measurements. We believe that this opposite behaviour was due to a difference we had in the sampling set-up. CRMLSCE usually operates with a PTFE filter at the inlet of the sampling line to prevent atmospheric particles entering the reactor; while CRM-MD did not use any filter for the intercomparison exercise. The PTFE filter might have act as water reservoir; retaining water vapours when the air was very humid and releasing water vapours when the air was dry. Therefore, using a filter at the inlet leads to both $\mathrm{C} 2$ drier or more humid than $\mathrm{C} 3$, depending on atmospheric conditions; while $\mathrm{C} 2$ of CRM-MD was always more humid than ambient air.

\subsection{Assessment of the correction for the kinetics regime}

As mentioned in Sect. 2.2, we use an experimental approach to estimate the correction factor that is needed to account for the deviation from pseudo first order kinetics during ambient measurements of $\mathrm{OH}$ reactivity. We introduced a known amount of $\mathrm{OH}$ reactivity produced by different gas standards in the reactors, including ethane and propane for both CRM instruments during the intercomparison on the field. Additional gases were also used during laboratory testing, before or after the field intercomparison, including isoprene for CRM-LSCE and ethene, propene, 
Table 2. Summary of correction stages applied to raw reactivity data for CRM-LSCE and CRM-MD. Correction coefficients are obtained from experiments as described in the section data analysis.

\begin{tabular}{lll}
\hline Correction & CRM-LSCE & CRM-MD \\
\hline Humidity & $12 \%$ & $4 \%$ \\
Kinetics & $\begin{array}{l}\text { Correction factor }= \\
1.71-0.38 \times \mathrm{Pyr} / \mathrm{OH} \\
(1 @ \mathrm{pyr} / \mathrm{OH}=1.86),\end{array}$ & $\begin{array}{l}\text { Correction factor }= \\
1.28-0.18 \times \mathrm{Pyr} / \mathrm{OH} \\
(1 @ \mathrm{pyr} / \mathrm{OH}=1.56)\end{array}$ \\
& $\begin{array}{l}\text { constant factor of } 0.98 \\
\text { applied }\end{array}$ & \\
1.36 & 1.31 \\
$\begin{array}{l}\text { Dilution } \\
\text { Overall increase } \\
\text { of raw data }\end{array}$ & & \\
due to corrections & $49 \%$ & $20 \%$ \\
\hline
\end{tabular}

and isoprene for CRM-MD. These standards are intended to be representative for the range of reactivity of ambient trace gases with $\mathrm{OH}$ (bimolecular rate constants in the range $10^{-13}-10^{-10} \mathrm{~cm}^{3}$ molecule $\mathrm{s}^{-1} \mathrm{~s}^{-1}$ ). Moreover, the standard of ethane used in the field and during laboratory tests was the same one for both instruments.

Tests made with gas standards covered a range of $\mathrm{OH}$ reactivity from the $\mathrm{LOD}\left(\approx 3 \mathrm{~s}^{-1}, 3 \sigma\right)$ up to $300 \mathrm{~s}^{-1}$. A smaller range of $\mathrm{OH}$ reactivity was investigated on CRMMD with values ranging from the $\mathrm{LOD}\left(\approx 3 \mathrm{~s}^{-1}, 3 \sigma\right)$ up to $65 \mathrm{~s}^{-1}$. However, tests performed in the laboratory using complex mixtures of NHMCs (non-methane hydrocarbons) and OVOCs (oxygenated volatile organic compounds) (see supplementary material of Michoud et al., 2015) showed that CRM-MD correctly measures higher $\mathrm{OH}$ reactivity values, with a linear response of the instrument up to approximately $900 \mathrm{~s}^{-1}$. The range of pyrrole-to-OH ratios investigated during these tests ranges from 1.2 to 2.6 , which is within the range of pyrrole-to-OH ratios observed during ambient measurements at Cape Corsica (1.2-2.6 for CRM-LSCE and 1.52.1 for CRM-MD).

Figure 6 shows results from the calibrations made for both CRMs on the field, using ethane (hollow circles) and propane (full circles) as gas standards. It is interesting to notice that the correction factor for both instruments seems to follow a linear dependency with the pyrrole-to- $\mathrm{OH}$ ratio inside the reactor. In particular, the correction factor decreases when higher ratios are achieved inside the reactor. This behaviour was shown to be reasonably well reproduced by modelling the chemistry inside the CRM (Michoud et al., 2015). Moreover, calibrations on CRM-LSCE reveal that a correction factor of 1 is reached for a pyrrole-to-OH ratio of 1.86 , while CRM-MD reaches 1 at a ratio of 1.56 . However, for pyrroleto-OH in the range 1.2-2.6 as the one of this study and showed in Fig. 6, such linear dependency seems to be fairly significant only for CRM-MD $\left(R^{2}=0.546\right)$, while it is not relevant for CRM-LSCE $\left(R^{2}=0.206\right)$. Therefore the data set from CRM-MD was corrected with the equation from the

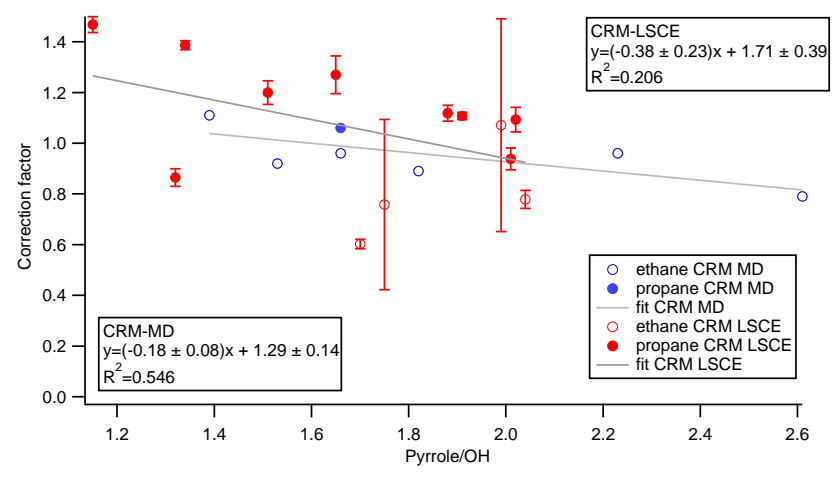

Figure 6. Correction factor of reactivity for the kinetics regime reported vs. pyrrole-to-OH ratio in the reactors. Correction for CRMLSCE is represented in red while correction for CRM-MD is represented in blue. Full circles refer to the experiments conducted with propane while hollow circles refer to the experiments with ethane as gas standard. Linear fits include coefficient values $\pm 1 \sigma$.

linear fit reported on Fig. 6 while the data set from CRMLSCE was corrected with a mean value of the correction factors obtained from the experiments conducted on the field. Since we obtained close corrections for our data sets $(0.98$ correction factor for CRM-LSCE, 0.97 for CRM-MD on average), this data processing did not substantially influence the correlation between the results from the two instruments. Table 2 reports a summary of the corrections resulting from our tests and their impact on the measures.

The second important point to notice from Fig. 6 is the larger variability in correction factors from the experiments observed for CRM-LSCE compared to CRM-MD ( $1 \sigma$ on the correction factor equals to 0.22 for CRM-LSCE and 0.07 for CRM-MD). We think that the main difference is attributable to a possible different mixing efficiency occurring inside the reactors where the two arms for air and nitrogen/OH are pointing. Although our reactors have the same shape, covering material and same flow rates injected, we suspect that even small differences in the length and pointing of the injection arms inside the reactor might provoke a different mixing and hence radical segregation inside the two systems. These differences in radical segregation could lead to differences in kinetics inside the two reactors. We need to further investigate different reactors to actually verify this hypothesis. To prevent that such small differences determine a wrong interpretation of the measured reactivity we consider therefore important that each CRM undergoes the experimental quantification of this correction factor; not only to assess the right correction for the kinetics regime but also to determine the specific reactor performance. Propane and ethane also showed slightly different behaviour when used as test gases for the CRM calibration. Different rate coefficients with $\mathrm{OH}$ could explain this behaviour, since for the same injected reactivity different concentration of the selected test gas are needed, hence the higher the concentration the closer 
the system is in the pseudo first order kinetics assumption. Additional experimental tests performed in the laboratory with a more reactive test gas as isoprene, and by modelled results of compounds with different reactivity conducted in the same pyrrole/OH range and discussed in the paper of $\mathrm{Mi}-$ choud et al. (2015), supported this hypothesis. However, the larger variability in the correction factors from all experimental field tests (propane and ethane) makes differences among test gases behaviour not significant in the evaluated range of pyrrole/OH, hence a mean value or a linear fit including all experimental results is suitable to correct the reactivity.

\subsection{Correction for dilution}

After corrections on $\mathrm{C} 2$ for changes in humidity between $\mathrm{C} 2$ and $\mathrm{C} 3$, and on the reactivity for deviations from the pseudo first order kinetics, we accounted for the dilution of the sampled air inside our reactors to determine the reactivity in ambient air. As mentioned in Sect. 2.2, such correction is calculated from the sampled flow rate of ambient air and the total flow rate within the reactor. Factors of 1.36 and 1.31 were calculated for CRM-LSCE and CRM-MD respectively, and a similar increase of our final data is therefore obtained.

\subsection{Measurement uncertainty}

Processed reactivity data are subject to three types of corrections, which impact the final result by $49 \%$ for CRM-LSCE and $20 \%$ by CRM-MD (Table 2). Among the discussed corrections, humidity differences play a more important role for CRM-LSCE while the other corrections influence the measurements from both instruments in a similar manner due to similar operating conditions.

Overall uncertainties include systematic errors and precision and were estimated according to the calculation described by Michoud et al. (2015). Systematic errors originates from the uncertainty on the rate coefficient between pyrrole and $\mathrm{OH}, k_{\text {pyrrole }+\mathrm{OH}}$, the uncertainty associated to the pyrrole standard, the stability of the PTR-MS sensitivity over time, the humidity and pseudo first order corrections described above and the correction for dilution. Such uncertainty is estimated to be $35 \%$ for CRM-LSCE and $18 \%$ for CRM-MD. Differences between instruments are due to the different uncertainties on the concentration of pyrrole in the standard cylinder (20\% for CRM-LSCE while $5 \%$ for CRMMD) and on the correction factor assessed for the kinetics regime ( $26 \%$ for CRM-LSCE while $9 \%$ for CRM-MD). The measurement precision depends on the concentration levels $\mathrm{C} 1, \mathrm{C} 2, \mathrm{C} 3$. The random error from precision dominates in the low range of $\mathrm{OH}$ reactivity (below $15 \mathrm{~s}^{-1}$ ) while systematic errors dominates for higher $\mathrm{OH}$ reactivity values. Overall uncertainty (systematic and precision) for this specific experiment, were estimated to be below $35 \%$ on average for CRM-LSCE for $\mathrm{OH}$ reactivity values higher than $8 \mathrm{~s}^{-1}$ and approximately $18 \%$ for CRM-MD when $\mathrm{OH}$ reactivity val- ues are higher than $15 \mathrm{~s}^{-1}$. For lower $\mathrm{OH}$ reactivity the overall uncertainty increases up to $50 \%$ at the LOD of $3 \mathrm{~s}^{-1}(3 \sigma)$ for both instruments (Michoud et al., 2015).

\subsection{Intercomparison of $\mathrm{OH}$ reactivity results}

Simultaneous measurements of $\mathrm{OH}$ reactivity with CRMLSCE and CRM-MD were conducted between the 8 and 13 July, 2013; the processing of the raw data was discussed in Sects. 3.2-3.5.

Figure 7 shows the correlation between reactivity data collected by CRM-LSCE ( $y$ axes) and CRM-MD ( $x$ axes) from their sampling (panel a, raw data) throughout their processing (panel $\mathrm{b}$ and $\mathrm{c}$, respectively data corrected for humidity differences and data corrected for deviation from the assumed kinetics) to the final results (panel d, reactivity in ambient air). Data points include three different sampling periods: a first plant enclosure test during $8-9$ July, ambient measurements between 10-11 July, and a second plant enclosure test between 12 and 13 July. As previously mentioned, to produce higher reactivity than ambient levels and extend our range of values for comparison we applied some stress on the plant to induce the emission of high levels of reactive compounds. In turn, our instruments responded to these high levels with small delays, and data acquisition was not perfectly synchronized, despite the fact that we achieved a residence time in the sampling lines on the same order of magnitude ( $12 \mathrm{~s}$ for CRM-LSCE and $13 \mathrm{~s}$ for CRM-MD). By consequence, small delays resulted in significant differences for high values of $\mathrm{OH}$ reactivity. We smoothed such differences considering thirty minutes averages of the measurements. Scatter plots therefore report all the data points obtained from our intercomparison experiment (190 points) and the agreement is quantified using linear least squares fit according to

$k_{\mathrm{OH}_{\mathrm{CRM}-\mathrm{LSCE}}}=b \cdot k_{\mathrm{OH}_{\mathrm{CRM}-\mathrm{MD}}}+a$.

Text boxes in Fig. 7 report an equation for each correlation plot, $1 \sigma$ standard deviation on the equation coefficients and the determination coefficients $R^{2}$ for the proportion of variability in the data sets.

These panels show a stepwise $(A \rightarrow D)$ increase in the level of correlation and a slight decrease in variability among data sets from the two instruments when each correction is subsequently applied. During the sampling, CRM-LSCE measured a lower reactivity compared to CRM-MD (19\% lower for the whole raw data set). Corrections for humidity changes and deviation from pseudo first order kinetics brought the results closer, with a difference of only $4 \%$. Finally, panel d shows that the correlation between the two data sets when the correction for ambient air dilution is applied is described by a slope of 1 and a coefficient $R^{2}$ of 0.75 ; which demonstrates that the results from the two instruments agree very well within the instrumental uncertainty. A linear least squares fit is also applied to the same data sets in a narrower range of 

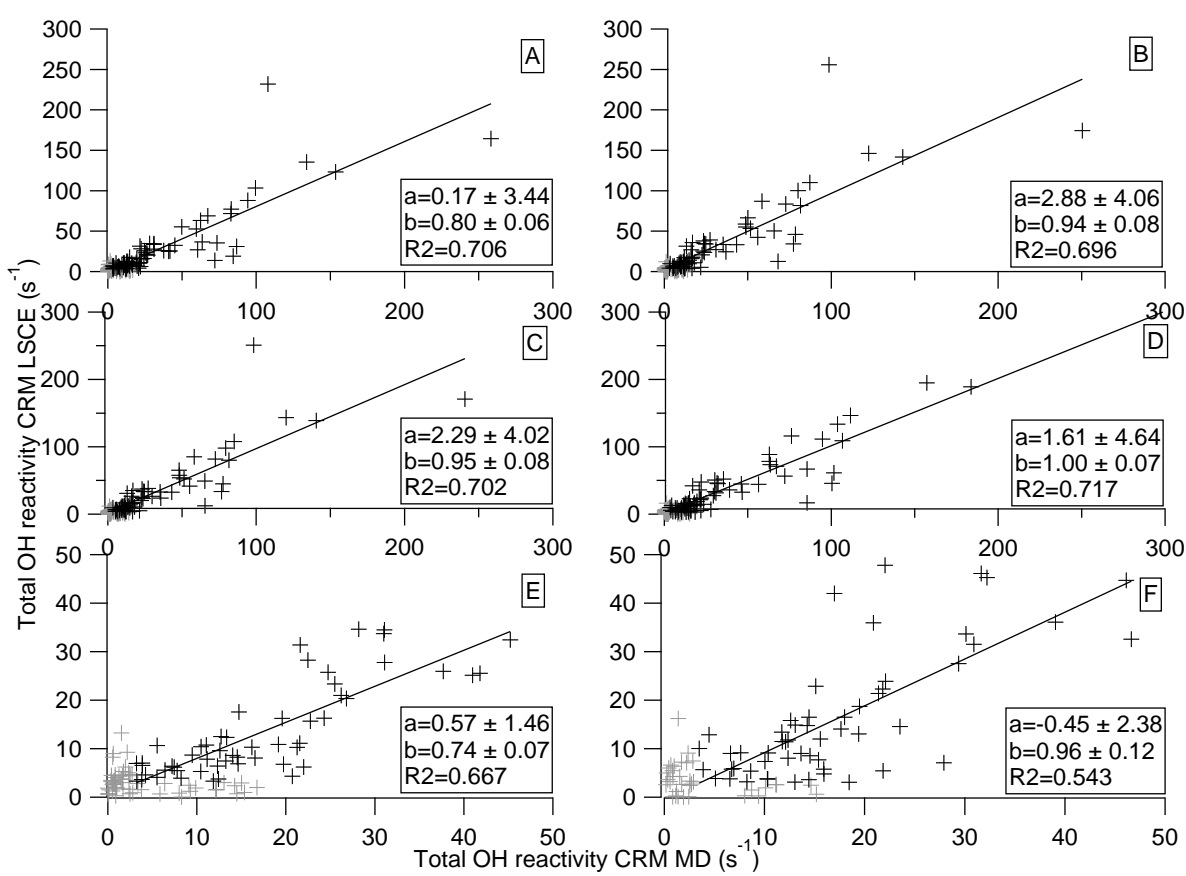

Figure 7. Linear least squares fits of total OH reactivity measured by CRM-LSCE vs. Total OH reactivity measured by CRM-MD. Panels from top left to bottom right show: correlation among raw results (a); correlation among data corrected for humidity (b); correlation among data corrected for humidity and deviation from pseudo first order kinetics (c); correlation among data corrected for humidity; kinetics regime and dilution inside the reactor (d); correlation among raw values in the range $0-50 \mathrm{~s}^{-1}$ (e); correlation among final values in the range $0-$ $50 \mathrm{~s}^{-1}$. (f). Coefficient values are extracted from the equation: $\mathrm{OH}$ reactivity CRM-LSCE $=b(\mathrm{OH}$ reactivity CRM-MD) $+a$ and report $1 \sigma$ standard deviation. The regressions are applied to the values above the instrumental LOD only.

reactivity values between 0 and $50 \mathrm{~s}^{-1}$ which is more relevant for the ambient $\mathrm{OH}$ reactivity values at the field site. For this range of values the variability among data is higher compared to the data points in the range $0-300 \mathrm{~s}^{-1}\left(R^{2}\right.$ from 0.667 to 0.543 vs. $R^{2}$ from 0.706 to 0.717 ). However, the agreement among CRM-LSCE and CRM-MD reactivity data sets also increases with the corrections applied when the 0 $50 \mathrm{~s}^{-1}$ range is considered. From the raw data to the final corrected reactivity in the interval $0-50 \mathrm{~s}^{-1}$ the slope of the fits varies from 0.74 (raw data), 0.93 (humidity corrected data), 0.92 (kinetics corrected data) to 0.96 (dilution corrected, final result). Therefore the two data sets show a good agreement, within the instrumental uncertainties, also for reactivity values below $50 \mathrm{~s}^{-1}$.

Figure 8 shows the time series of ambient $\mathrm{OH}$ reactivity measured by CRM-LSCE (red data points) and CRM-MD (blue data points). Data points refer to fully corrected results from the three periods of exercise including plant enclosure and ambient air measurements. The signal measured by the PTR-MS of CRM-LSCE at $m / z$ 137, which corresponds to the unfragmented protonated mass of total monoterpenes, is also reported as a reference for reactive biogenic VOCs, in particular for the plant enclosure test. Peaks emerging during the plant enclosure tests were obtained from induced plant emissions (8-9 July and 12-13 July). As Fig. 8 shows, $\mathrm{OH}$ reactivity peaked when $m / z 137$ peaked and signals from
CRM-LSCE, CRM-MD and PTR-MS during the whole test exhibit the same variability. The method also demonstrated the real time quick response to the induced plant emissions.

It is worth noticing that this exercise was run on only two instruments which were also operated under similar conditions. It would be therefore very interesting to conduct this type of exercises on a larger number of CRMs, operated with different settings and in various environments. This would allow determining work cases when different corrections need to be applied and getting more insights on the impact they have on reactivity. However, intercomparison exercises for CRM instruments alone cannot help identifying specific and still unknown analytical issues for this technique. Therefore, experiments involving CRM and other techniques would be of greater interest.

\section{Summary and conclusions}

Our study presents results of the first intercomparison exercise reported on two Comparative Reactivity Method instruments assembled in different laboratories and used under similar operating conditions at the field site of Ersa, Cape Corsica, France. The two instruments discussed here are CRM-LSCE and CRM-MD, from the laboratories LSCE (Laboratoire des Sciences du Climat et de l' Environnement) 


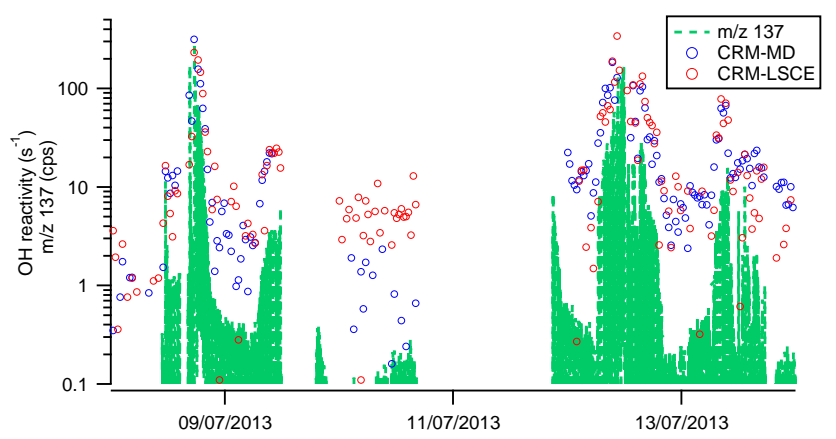

Figure 8. Time series of enclosure $\mathrm{kOH}$ (8-9 July), ambient $\mathrm{kOH}$ (10-11 July), enclosure kOH (12-13 July) measured by CRMLSCE (red) and CRM-MD (blue). Total monoterpenes signal measured by CRM-LSCE as protonated unfragmented $m / z 137$ is reported with the green line.

and MD (Mines de Douai) where they were assembled. The intercomparison took place during early July 2013 in the frame of the ChArMEx project (Chemistry and Aerosols in a Mediterranean Experiment). It consisted of different calibration and validation tests of the instruments as well as simultaneous measurements of $\mathrm{OH}$ reactivity.

We here present for the first time an alternative approach to rapidly measure the initial concentration of pyrrole $(\mathrm{C} 1)$ without perturbing the system. The method consists in introducing an $\mathrm{OH}$ scavenger in the reactor, when the system is measuring $\mathrm{C} 2$ under wet conditions. The scavenger, methane in this study, reacts with most of the $\mathrm{OH}$ radicals available for reaction with pyrrole and/or any other ambient molecule. Therefore, even if the cell is wet, and $\mathrm{OH}$ radicals are produced, the amount of pyrrole reacting with $\mathrm{OH}$ is negligible, and its actual level would be $\mathrm{C} 1$. The main advantage of this alternative approach is a substantial reduction in the conditioning time from several $10 \mathrm{~s}$ of minutes to a few minutes. Such improvement is particularly useful during field works.

We document in detail the corrections needed to treat a data set of reactivity measured by CRM and use an alternative experimental approach to correct for deviations from first order kinetics. Humidity differences between $\mathrm{C} 2$ and $\mathrm{C} 3$ arise even when using a catalytic converter to generate zero air. The corrections applied for humidity influence the raw data of $4 \%$ (CRM-MD) and $12 \%$ (CRM-LSCE) on average. We showed how the instruments response changed by introducing known amounts of reactivity in the kinetics regime of pyrrole-to-OH ratios ranging from 1.2-2.6. In particular, we saw that the correction factor needed to account for a deviation from pseudo first order conditions is close to unity.

When the three corrections for humidity differences, deviations from first order kinetics, and dilution are applied they have an average impact on the two data sets of $20 \%$ for CRM-MD and $49 \%$ for CRM-LSCE.

We also tested the ability of the two instruments in measuring $\mathrm{OH}$ reactivity over a broad range of values from the instruments LOD $\left(3 \mathrm{~s}^{-1}\right)$ to approximately $300 \mathrm{~s}^{-1}$. Correlations between 30 min averaged data resulted in CRM LSCE measurements being extremely close to CRM MD measurements, a correlation described by a linear least squares fit with a slope of 1 and a $R^{2}$ of 0.75 . This excellent agreement among our results consolidates the robustness of the comparative reactivity method to measure $\mathrm{OH}$ reactivity. Our study also stresses out the intensive data processing for this method and the importance of a proper determination of each correction needed to process the data for each instrument.

Finally, more intercomparison exercises among CRM instruments, and among different methods used to measure $\mathrm{OH}$ reactivity would be of great interest to evaluate the limitations and strengths of this technique.

Acknowledgements. This study was supported by the European Commission's 7th Framework Programme under grant agreement number 287382 "PIMMS" and under grant agreement number 293897, "DEFIVOC". Financial support was also received from ChArMEx, PRIMEQUAL CARBO-SOR, CNRS, CEA, and the CaPPA project (chemical and physical properties of atmosphere), which is funded by the French National Research Agency (ANR) through PIA (Programme d'Investissement d'Avenir) under contract ANR-11-LABX-0005-01 and by the Regional Council Nord-Pas de Calais and the European Funds for Regional Economic Development (FEDER). We thank F. Dulac, E. Hamonou for managing the ChArMEx project and A. Borbon for the CARBO-SOR project, as well as all the scientists, engineers and students involved in the field campaign at Cape Corsica for their support. We acknowledge J. Williams and his group at MPIC for providing the glass reactors for our instruments.

Edited by: C. Reeves

\section{References}

Ammann, C., Brunner, A., Spirig, C., and Neftel, A.: Technical note: Water vapour concentration and flux measurements with PTR-MS, Atmos. Chem. Phys., 6, 4643-4651, doi:10.5194/acp6-4643-2006, 2006.

Archibald, A. T., Petit, A. S., Percival, C. J., Harvey, J. N., and Shallcross, D. E.: On the importance of the reaction between $\mathrm{OH}$ and $\mathrm{RO}_{2}$ radicals, Atmos. Sci. Lett., 10, 102-108, doi:10.1002/asl.216, 2009.

Atkinson, R., Aschmann, S. M., Winer, A. M., and Carter, W. P. L.: Rate constants for the gas phase reactions of $\mathrm{OH}$ radicals and O3 with pyrrole at $295 \pm 1 \mathrm{~K}$ and atmospheric pressure, Atmos. Environ., 18, 2105-2107, doi:10.1016/0004-6981(84)90196-3, 1984.

Atkinson, R., Baulch, D. L., Cox, R. A., Crowley, J. N., Hampson, R. F., Hynes, R. G., Jenkin, M. E., Rossi, M. J., and Troe, J.: Evaluated kinetic and photochemical data for atmospheric chemistry: Volume III - gas phase reactions of inorganic halogens, Atmos. Chem. Phys., 7, 981-1191, doi:10.5194/acp-7-981-2007, 2007.

Bracho-Nunez, A., Welter, S., Staudt, M., and Kesselmeier, J.: Plant-specific volatile organic compound emission rates from 
young and mature leaves of Mediterranean vegetation, J. Geophys. Res.-Atmos., 116, D16304, doi:10.1029/2010JD015521, 2011.

Calpini, B., Jeanneret, F., Bourqui, M., Clappier, A., Vajtai, R., and van den Bergh, H.: Direct measurement of the total reaction rate of $\mathrm{OH}$ in the atmosphere, Analusis, 27, 328-336, doi:10.1051/analusis:1999270328, 1999.

Di Carlo, P. D., Brune, W. H., Martinez, M., Harder, H., Lesher, R., Ren, X., Thornberry, T., Carroll, M. A., Young, V., Shepson, P. B., Riemer, D., Apel, E., and Campbell, C.: Missing OH Reactivity in a Forest: Evidence for Unknown Reactive Biogenic VOCs, Science, 304, 722-725, doi:10.1126/science.1094392, 2004.

Dillon, T. J., Tucceri, M. E., Dulitz, K., Horowitz, A., Vereecken, L., and Crowley, J. N.: Reaction of Hydroxyl Radicals with C4H5N (Pyrrole): Temperature and Pressure Dependent Rate Coefficients, J. Phys. Chem. A, 116, 6051-6058, doi:10.1021/jp211241x, 2012.

Dolgorouky, C., Gros, V., Sarda-Esteve, R., Sinha, V., Williams, J., Marchand, N., Sauvage, S., Poulain, L., Sciare, J., and Bonsang, B.: Total $\mathrm{OH}$ reactivity measurements in Paris during the 2010 MEGAPOLI winter campaign, Atmos. Chem. Phys., 12, 95939612, doi:10.5194/acp-12-9593-2012, 2012.

Dusanter, S., Vimal, D., Stevens, P. S., Volkamer, R., and Molina, L. T.: Measurements of $\mathrm{OH}$ and $\mathrm{HO}_{2}$ concentrations during the MCMA-2006 field campaign - Part 1: Deployment of the Indiana University laser-induced fluorescence instrument, Atmos. Chem. Phys., 9, 1665-1685, doi:10.5194/acp-9-1665-2009, 2009.

Faloona, I. C., Tan, D., Lesher, R. L., Hazen, N. L., Frame, C. L., Simpas, J. B., Harder, H., Martinez, M., Carlo, P. D., Ren, X., and Brune, W. H.: A Laser-induced Fluorescence Instrument for Detecting Tropospheric $\mathrm{OH}$ and $\mathrm{HO}_{2}$ : Characteristics and Calibration, J. Atmos. Chem., 47, 139-167, doi:10.1023/B:JOCH.0000021036.53185.0e, 2004.

Fittschen, C., Whalley, L. K., and Heard, D. E.: The Reaction of $\mathrm{CH} 3 \mathrm{O} 2$ Radicals with $\mathrm{OH}$ Radicals: A Neglected Sink for $\mathrm{CH}_{3} \mathrm{O}_{2}$ in the Remote Atmosphere, Environ. Sci. Technol., 48, 7700-7701, doi:10.1021/es502481q, 2014.

Fuchs, H., Hofzumahaus, A., Rohrer, F., Bohn, B., Brauers, T., Dorn, H.-P., Häseler, R., Holland, F., Kaminski, M., Li, X., Lu, K., Nehr, S., Tillmann, R., Wegener, R., and Wahner, A.: Experimental evidence for efficient hydroxyl radical regeneration in isoprene oxidation, Nat. Geosci., 6, 1023-1026, doi:10.1038/ngeo1964, 2013.

Goldstein, A. H. and Galbally, I. E.: Known and Unexplored Organic Constituents in the Earth's Atmosphere, Environ. Sci. Technol., 41, 1514-1521, doi:10.1021/es072476p, 2007.

Hansen, R. F., Griffith, S. M., Dusanter, S., Rickly, P. S., Stevens, P. S., Bertman, S. B., Carroll, M. A., Erickson, M. H., Flynn, J. H., Grossberg, N., Jobson, B. T., Lefer, B. L., and Wallace, H. W.: Measurements of total hydroxyl radical reactivity during CABINEX 2009 - Part 1: field measurements, Atmos. Chem. Phys., 14, 2923-2937, doi:10.5194/acp-14-2923-2014, 2014.

Hansen, R. F., Blocquet, M., Schoemaecker, C., Léonardis, T., Locoge, N., Fittschen, C., Hanoune, B., Stevens, P. S., Sinha, V., and Dusanter, S.: Intercomparison of the comparative reactivity method (CRM) and pump-probe technique for measuring total $\mathrm{OH}$ reactivity in an urban environment, Atmos. Meas. Tech. Discuss., 8, 6119-6178, doi:10.5194/amtd-8-6119-2015, 2015.
Hens, K., Novelli, A., Martinez, M., Auld, J., Axinte, R., Bohn, B., Fischer, H., Keronen, P., Kubistin, D., Nölscher, A. C., Oswald, R., Paasonen, P., Petäjä, T., Regelin, E., Sander, R., Sinha, V., Sipilä, M., Taraborrelli, D., Tatum Ernest, C., Williams, J., Lelieveld, J., and Harder, H.: Observation and modelling of HOx radicals in a boreal forest, Atmos. Chem. Phys., 14, 8723-8747, doi:10.5194/acp-14-8723-2014, 2014.

Hofzumahaus, A., Rohrer, F., Lu, K., Bohn, B., Brauers, T., Chang, C.-C., Fuchs, H., Holland, F., Kita, K., Kondo, Y., Li, X., Lou, S., Shao, M., Zeng, L., Wahner, A., and Zhang, Y.: Amplified Trace Gas Removal in the Troposphere, Science, 324, 1702 1704, doi:10.1126/science.1164566, 2009.

Ingham, T., Goddard, A., Whalley, L. K., Furneaux, K. L., Edwards, P. M., Seal, C. P., Self, D. E., Johnson, G. P., Read, K. A., Lee, J. D., and Heard, D. E.: A flow-tube based laser-induced fluorescence instrument to measure $\mathrm{OH}$ reactivity in the troposphere, Atmos. Meas. Tech., 2, 465-477, doi:10.5194/amt-2-465-2009, 2009.

Jeanneret, F., Kirchner, F., Clappier, A., van den Bergh, H., and Calpini, B.: Total VOC reactivity in the planetary boundary layer: 1. Estimation by a pump and probe $\mathrm{OH}$ experiment, J. Geophys. Res.-Atmos., 106, 3083-3093, doi:10.1029/2000JD900602, 2001.

Kim, S., Guenther, A., Karl, T., and Greenberg, J.: Contributions of primary and secondary biogenic VOC tototal $\mathrm{OH}$ reactivity during the CABINEX (Community Atmosphere-Biosphere INteractions Experiments)-09 field campaign, Atmos. Chem. Phys., 11, 8613-8623, doi:10.5194/acp-11-8613-2011, 2011.

Kovacs, T. A. and Brune, W. H.: Total OH Loss Rate Measurement, J. Atmos. Chem., 39, 105-122, doi:10.1023/A:1010614113786, 2001.

Kumar, V. and Sinha, V.: VOC-OHM: A new technique for rapid measurements of ambient total $\mathrm{OH}$ reactivity and volatile organic compounds using a single proton transfer reaction mass spectrometer, Int. J. Mass Spectrom., 374, 55-63, doi:10.1016/j.ijms.2014.10.012, 2014.

Lindinger, W. and Jordan, A.: Proton-transfer-reaction mass spectrometry (PTR-MS): on-line monitoring of volatile organic compounds at pptv levels, Chem. Soc. Rev., 27, 347-375, doi:10.1039/A827347Z, 1998.

Lou, S., Holland, F., Rohrer, F., Lu, K., Bohn, B., Brauers, T., Chang, C.C., Fuchs, H., Häseler, R., Kita, K., Kondo, Y., Li, X., Shao, M., Zeng, L., Wahner, A., Zhang, Y., Wang, W., and Hofzumahaus, A.: Atmospheric $\mathrm{OH}$ reactivities in the Pearl River Delta - China in summer 2006: measurement and model results, Atmos. Chem. Phys., 10, 11243-11260, doi:10.5194/acp-10-11243-2010, 2010.

Martinez, M., Harder, H., Kovacs, T. A., Simpas, J. B., Bassis, J., Lesher, R., Brune, W. H., Frost, G. J., Williams, E. J., Stroud, C. A., Jobson, B. T., Roberts, J. M., Hall, S. R., Shetter, R. E., Wert, B., Fried, A., Alicke, B., Stutz, J., Young, V. L., White, A. B., and Zamora, R. J.: $\mathrm{OH}$ and $\mathrm{HO}_{2}$ concentrations, sources, and loss rates during the Southern Oxidants Study in Nashville, Tennessee, summer 1999, J. Geophys. Res., 108, 4617, , doi:10.1029/2003JD003551, 2003.

Mao, J., Ren, X., Brune, W. H., Olson, J. R., Crawford, J. H., Fried, A., Huey, L. G., Cohen, R. C., Heikes, B., Singh, H. B., Blake, D. R., Sachse, G. W., Diskin, G. S., Hall, S. R., and Shetter, R. E.: Airborne measurement of $\mathrm{OH}$ reactivity during INTEX-B, 
Atmos. Chem. Phys., 9, 163-173, doi:10.5194/acp-9-163-2009, 2009.

Michoud, V., Hansen, R. F., Locoge, N., Stevens, P. S., and Dusanter, S.: Detailed characterizations of the new Mines Douai comparative reactivity method instrument via laboratory experiments and modeling, Atmos. Meas. Tech., 8, 3537-3553, doi:10.5194/amt-8-3537-2015, 2015.

Nölscher, A. C., Sinha, V., Bockisch, S., Klüpfel, T., and Williams, J.: Total $\mathrm{OH}$ reactivity measurements using a new fast Gas Chromatographic Photo-Ionization Detector (GC-PID), Atmos. Meas. Tech., 5, 2981-2992, doi:10.5194/amt-5-2981-2012, 2012a.

Nölscher, A. C., Williams, J., Sinha, V., Custer, T., Song, W., Johnson, A. M., Axinte, R., Bozem, H., Fischer, H., Pouvesle, N., Phillips, G., Crowley, J. N., Rantala, P., Rinne, J., Kulmala, M., Gonzales, D., Valverde-Canossa, J., Vogel, A., Hoffmann, T., Ouwersloot, H. G., Vilà-Guerau de Arellano, J., and Lelieveld, J.: Summertime total $\mathrm{OH}$ reactivity measurements from boreal forest during HUMPPA-COPEC 2010, Atmos. Chem. Phys., 12, 8257-8270, doi:10.5194/acp-12-8257-2012, 2012b.

Nölscher, A. C., Bourtsoukidis, E., Bonn, B., Kesselmeier, J., Lelieveld, J., and Williams, J.: Seasonal measurements of total $\mathrm{OH}$ reactivity emission rates from Norway spruce in 2011, Biogeosciences, 10, 4241-4257, doi:10.5194/bg-10-4241-2013, 2013.

Paulson, S. E., Chung, M. Y., and Hasson, A. S.: OH Radical Formation from the Gas-Phase Reaction of Ozone with Terminal Alkenes and the Relationship between Structure and Mechanism, J. Phys. Chem. A, 103, 8125-8138, doi:10.1021/jp991995e, 1999.
Sadanaga, Y., Yoshino, A., Watanabe, K., Yoshioka, A., Wakazono, Y., Kanaya, Y., and Kajii, Y.: Development of a measurement system of $\mathrm{OH}$ reactivity in the atmosphere by using a laserinduced pump and probe technique, Rev. Sci. Instrum., 75, 2648 2655, doi:10.1063/1.1775311, 2004.

Sinha, V., Williams, J., Crowley, J. N., and Lelieveld, J.: The Comparative Reactivity Method - a new tool to measure total $\mathrm{OH}$ Reactivity in ambient air, Atmos. Chem. Phys., 8, 2213-2227, doi:10.5194/acp-8-2213-2008, 2008.

Sinha, V., Custer, T. G., Kluepfel, T., and Williams, J.: The effect of relative humidity on the detection of pyrrole by PTR-MS for $\mathrm{OH}$ reactivity measurements, Int. J. Mass Spectrom., 282, 108-111, doi:10.1016/j.ijms.2009.02.019, 2009.

Sinha, V., Williams, J., Diesch, J. M., Drewnick, F., Martinez, M., Harder, H., Regelin, E., Kubistin, D., Bozem, H., HosaynaliBeygi, Z., Fischer, H., Andrés-Hernández, M. D., Kartal, D., Adame, J. A., and Lelieveld, J.: Constraints on instantaneous ozone production rates and regimes during DOMINO derived using in-situ $\mathrm{OH}$ reactivity measurements, Atmos. Chem. Phys., 12, 7269-7283, doi:10.5194/acp-12-7269-2012, 2012.

Yoshino, A., Sadanaga, Y., Watanabe, K., Kato, S., Miyakawa, Y., Matsumoto, J., and Kajii, Y.: Measurement of total OH reactivity by laser-induced pump and probe technique - comprehensive observations in the urban atmosphere of Tokyo, Atmos. Environ., 40, 7869-7881, doi:10.1016/j.atmosenv.2006.07.023, 2006. 